\title{
Implications for Asset Management in the Broadcasting Industry arising from Industrial Revolution 4.0
}

\author{
Ponnan R., Supramaniam M, Abdullah A
}

\begin{abstract}
The Industrial Revolution 4.0 and the Internet of Things pose numerous challenges for broadcasters in Malaysia. Archiving content and production workflow are critical in the transition to the digital environment. Issue of resource expansion and loss of opportunity among small and medium-sized broadcasters are a result of technological disruption at the advent of IR 4.0. Large amount of content requires digitisation following new quality control (QC) standards in the transition to digitalisation. In this exploratory study, a scalable media asset management (MAM) solution especially for small-scale content providers is proposed. The aim is to establish: (1) the challenges experienced by audio-visual archives, (2) metadata features for effective MAM processes and (3) efficiency among talents to facilitate large volume of transactions in the MAM workflow. In this qualitative research, face-to-face in-depth interviews with broadcasters, content providers and vendors at their respective premises and participant observation and content analysis were conducted at production operation centres and production houses to understand their issues. A compliance criteria model compatible to their workflow is proposed.
\end{abstract}

Keywords: broadcasting archives, metadata, machine learning, and media asset management.

\section{INTRODUCTION}

Converging technologies and digitization is changing models of operations creating exacerbated inequality among broadcasters [1]. The fourth industrial revolution is only fueling the inevitable change. Most broadcast processes would soon become redundant when artificial intelligence and machine learning are embedded into the broadcast processes. Broadcasters are seeking ways and means to brace with global trends in asset management. The main challenge related to the role of audio-visual archives in the wake of IR 4.0 can be situated within the media asset management (MAM) workflow in broadcasting organisations, especially when content become digitised and processes become networked [2].

Broadcasters in Malaysia have almost completely migrated from their traditional broadcasting practices to advanced

Revised Manuscript Received on August 18, 2019

Ramachandran Ponnan, School of Media and Communication, Taylors University,

Mahadevan Subramaniam, Institute of Graduate Studies, SEGi University,

Azween Abdullah,; School of Computing and IT, Taylors University.

digital broadcasting processes and are ready for analogue shut-off at the end of 2019. Currently, each part of the multimedia service offered by system manufacturers and designers is developed to fulfil the varying needs of the respective broadcaster. Broadcaster content management or MAM systems are expected to constantly evolve and be upgraded, resulting in significant resources being spent on re-inventing and re-writing media management systems. MAM located under the broad umbrella of digital asset management (DAM) is primed for managing media assets efficiently. The authors of $[3,4]$ posited that the content processing cycle of media management consists of the following stages: (i) ingest, (ii) create metadata, (iii) set storage/content repository, (iv) access, (v) transform/re-purpose and (vi) distribute. The downside of ineffective archives and MAM is that they lead to the loss of opportunity at the re-purposing and content re-broadcasting stages after archiving.

Content in archives is meant to endure. End users do not need to re-invent content, but only to re-purpose it for multimedia broadcasting [5]. Broadcasters and the society recognise its value but shy away from systematic preservation. Hence, the proposed model, which enhances the end-to-end MAM workflow from archiving processes, through systematic documentation, up to on-air transmission, would be useful for broadcasters and vendors, especially those of small size. The availability of such a model would result in zero or minimal rejection at the technical and content quality control (QC) stage before transmission.

\section{A. Problem Statement}

Technological problems have disrupted operations in the broadcasting industry from time to time. Poor compliance to evolving standards have affected the systematic executions of workflow, indexing, archiving and retrieval of content in broadcasting organizations. Established and resourceful broadcasters are gradually coping with industrial disruptions. However, small and medium-sized content producers and vendors have to work harder at solutions.

The archiving process is affected by ineffective adherence to the metadata requirements. There exist a lack of harmonization during content search using keywords in the archives among users. 
While resourceful broadcasters are coping with this disruption, small- and medium-sized content producers and vendors are struggling to resolve this problem. Non-compliance, ineffective metadata and product rejection cause loss of opportunity for broadcasters. Programmes are rejected at the final transmission stage, when they are subjected to technical quality control.

Broadcast content for storage and submission for broadcasting with the expected technical and content quality standards, must be learnt and complied by vendors Standards must match expected quality parameters for a seamless broadcasting experience. This is the major problem among the broadcasters. Vendors are most affected who find it difficult to cope with the expected technical standards. A 1,300 strong-registered vendors support the Malaysian creative industry, but only about 800 of them are active. These vendors contribute a vital $40 \%-60 \%$ of airtime content each year.

The current processes have outlived existing MAM systems, which are not sufficiently flexible to cope with the changes in the digital environment. Besides, the deluge of content from the programming side $(85 \%)$, content from the news division constitutes about $15 \%$ of the total airtime (RTM). Typically, incoming content from a variety of sources for airtime are found in four categories: (1) in-house production, (2) private local productions from SMEs (vendors), (3) syndicated overseas programmes from vendors, looping productions or repeat programmes and (4) news and current affairs partly contributed by stringers.

\section{B. Research Questions}

1) How does IR 4.0 challenge the work process at the audio-visual archives?

2) How can MAM improve efficiency of SMEs workflow?

3) How do SME's comply with an efficient broadcasting workflow?

\section{LITERATURE REVIEW}

\section{A. Formats of Indexing}

Archives using metadata standards resort to the index-editor or the PBCore metadata standard, for example: eFilm_ReSources_L1: contains the Llannotation names. L1 and L2 relate to the Level 1 and Level 2 descriptive categories in the PBCore metadata structure [5].

In addition, the Oral History Metadata - that creates metadata is a back-end system, where the archivist processes content for the front-end user linked to a W3C's eXtensible Metadata Language (XML) file displaying the required metadata used for retrieval from the archive [6].

Besides multiple formats of archive storages, the search for required titles and clips of historical content is problematized by the use of unrelated and too many keywords. At the same time, similar content is also available in multiple languages [7].

Instead, automatic image cataloguing for DAM is also suggested [8]. This method allows uploading and retrieval processes seamlessly that enables ease of location and tracking at will by clients. Unfortunately, some would try to claim otherwise. IBM's Visual Recognition, Adobe's Smart Tag and Extensis are some of such examples. Such cataloguing technology can be tailor made for machine learning of content archival purposes and quality control before the end of the workflow. Broadcasters have the option of repurposing archived content for alternative programming or future distribution.

Archiving existing and new content begins at the ingest stage, followed by embedding metadata and file format (e.g. B/W 65GB assets, M4V digital video for streaming from an open source). A reader or a photo-editing application to extract embedded data is required for editing and repurposing for further use [9].

\section{B. Metadata}

In order to achieve seamless content management, there must be an agreed structural format for metadata presentation to be accessed and decoded. Next, various attribute terms (vocabulary) used must be standardised so that content could be processed intelligently [9]. For example, the vendor attributes or the date attribute can mean the creation date, the expiry date, the date of birth. The processing component must be able to interpret the metadata vocabulary correctly given its current context. There has been significant work done by various industrial bodies to propose domain specific metadata vocabularies (e.g. IEEE Learning Objects Metadata for educational material) [10].

Numerous media intelligent applications are available for MAM [11]. Yet, such applications do not mesh with the needs of the small producers and vendors [3]. According to [12], there is yet to emerge a unified system for the organisation of content for retrieval, much less a lasting system for digital content storage and retrieval.

\section{Conceptual Framework}

Experts in the Industry recommend The Content Management System (CMS) as the Standard model [2] that offers adaptations as a conceptual framework for the study.

The MAM workflow includes an indexing system that reduces manual management of incoming content for storage. The workflow provides for efficient documentation for monetization of archived material. The CMS model is often adapted to real-time situations by production companies. Technical and production QC features are articulated for producers before putting content through the workflow. The model outlines the main features of a practical MAM system.

\begin{tabular}{l|ll} 
Ingest & Manage & Distribute \\
Indexing and & Master control & Technical \\
Creation of & Room & Gate-keeping \\
metadata & Or &
\end{tabular}




\begin{tabular}{|c|c|c|}
\hline & Production & Content \\
\hline Embedded & Operations & Delivery and \\
\hline Applications & Centre (POC) & $\begin{array}{l}\text { Syndication to } \\
\text { clients }\end{array}$ \\
\hline Incoming & Short-term & On-wards \\
\hline $\begin{array}{l}\text { Content } \\
\text { Acauisition }\end{array}$ & archive and & processing for \\
\hline $\begin{array}{l}\text { Acquisition } \\
\text { Deep Archives }\end{array}$ & $\begin{array}{l}\text { brorage for } \\
\text { call }\end{array}$ & $\begin{array}{l}\text { on-air } \\
\text { broadcast }\end{array}$ \\
\hline
\end{tabular}

Fig. 1. Adaptation from CMS for a scaled framework of the MAM workflow [2].

Figure 1 illustrates a generic MAM or CMS model articulating possible functions to be included into the following three main processes: (1) ingest, (2) manage and (3) distribute.

The CMS model addresses content process management that follows a two-tier model. The top tier is a generic three-step flow of ingest, manage and deliver or deploy, generally found at most broadcast workflow. Below these steps, a detailed set of functions provide an interface to enable the integration of incoming content, construction of metadata, technology for various applications and the final programs for transmission. This process is scalable and suits vendors and small-time producers.

However, a conceptual framework in figure 2 that addresses the research questions of the study is an adaptation from The Human Capital Theory [13], The contingency theory [14] and the DAM Maturity Model [15]. The dependent variable of the study is improving efficiency of Malaysian SME's while the independent variables are knowledge, skills, task/roles, environment and system. The independent variables and dependent variable are mediated by technology sustainability, derived from theories and literature. The framework offers a more tangible solution based approach to the study.

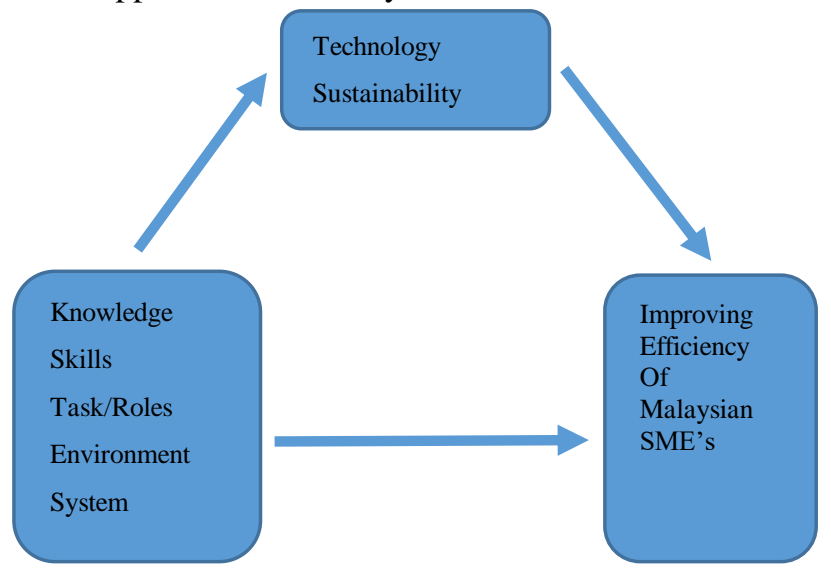

Fig. 2: Conceptual Framework for Efficiency and Effectiveness

\section{METHOD}

These exploratory, qualitative research methods [13] led to face-to-face in-depth interviews through snowballing at various premises of informants in the Klang Valley, Kelantan and Kuching. Forty subject matter experts from four mainstream broadcasters and twelve vendors were interviewed. They also provided participant observation and content analysis opportunities at their production operation centres (POC), archives, vendors' production processes and television editing tables.

Participant observation [14] of (a) the workflow of programmes input to the archives, (b) newsroom archives and workflow, (c) MAM processes at the POC, QC unit and (d) on-air play out centre was performed.

The analysis of textual content was Open Coding that included labelling concepts, defining and developing categories based on retrieved information. This content was used to analyze qualitative information as Qualitative data analysis method like Grounded Theory.

\section{RESULTS AND DISCUSSION}

Interviews, observations and content analysis provided varying outcome that differed from some of the practices elsewhere in the Broadcasting Industry. One general fact established though is the technological disruption experienced by broadcasters that is demanding urgent and systematic intervention.

\section{A. Improving workflow at archives}

Broadcasters are effectively installing intervention strategies in stages where they are urgently needed. The MAM archiving processes are expected to be fully digitised first for them to be compatible for machine to read and recognise content efficiently in the workflow. The MAM process recognises two kinds of digitised content in storage: deep archive and online storage. The deep archive is a storage for next transmission (within six months), whereas the online storage is meant for the current transmission (within a week). The system is able to search any indexed material in the deep archive and restore it to the online storage after use. The workflow cascades as Ingest, Manage and Distribute.

\section{- Ingest}

The first issue here is the improper indexing of incoming content by the archivists who use a standard field for machine recognition. The vocabulary used is 'speaking in different languages' or incomprehensible. Secondly, the playback machines used at the archive are outdated and cannot be restored to work efficiently, and the content itself is available in multiple formats. These issues must be resolved first.

The engineer in charge at the POC said, 'Production materials, raw footages and edited footages meant for post-production are purposefully catalogued using simple metadata for ingestion'. He also said, 'Technicians are well-trained specialists because they work at their specific area. Technicians performing ingestion will only focus on ingestion and those in charge of storing will know all about the storage processes'. 
He continued, 'Some of material in the archive is of poor quality, for example, Opah (1983), the drama shot in a $16 \mathrm{~mm}$ film. We have digitised the footages but we still need to mend it from black and white films with scratches. For some of P. Ramlee's films, the reels are torn. These are some of the challenges in restoring the quality of the archived material before ingestion'.

\section{- Manage}

Several short-term archive strategies and storage for broadcasting call have to be managed as ingestion of content into the online storage starts four days before transmission. The MAM system at the archive is different. MAM operates under the broader umbrella of Digital Asset Management. For example, MAM is responsible for transmission, where files are stored in formats called 'OP1' and 'OPATEM', which are different. In MAM, content appended audio and video, one file comes with audio, video and the header. In DAM, it comes with video and four audios or eight audios separately. When content specific title is required for transmission, it is compressed and retrieved from the archive.

\section{- Distribute}

The engineer at the POC also said, 'In the MAM process, segmentation within a programme occurs a few times. For example, a one-hour programme will be chopped into four blocks for the insertion of commercials, promos and PSAs. Once on air, the system will insert them. This is what the MAM system or machine learns ' what to do and what should be done' before program distribution.

The digital interactive section at the pre-transmission stage will enforce compulsory QC at the end of the MAM process. When QC is completed, the content is sent back to the beginning of the process to be ingested into the MAM system. Every item is indexed to the MAM specification. Two copies are created: one copy of the content is ingested into the MAM process and the other master copy is printed into the XDCAM format without re rendering and sent to the deep archive.

\section{B. File base format for metadata tracking}

A file-based format is recommended for multimedia content providers to comply. They need to learn basic metadata field requirements for their content to be compatible to the house MAM workflow.Equations.

Therefore, vendors should send their content in recommended file-based formats. Vendors are given two formats (codec options): XDCAM 422 and Apple Processor 422.

\section{- Metadata Field}

General MAM metadata fields required are not limited to, media format, media ID, title, episode, duration, segments of content (Table 1).

Table 1: Metadata recognised by DAM and MAM systems.

$$
\begin{aligned}
& \text { - Media ID } \\
& \text { - Media format: audio \& video standards } \\
& \text { - Title of content } \\
& \text { - Producer } \\
& \text { - Date of production } \\
& \text { - Location } \\
& \text { - Episode(s) } \\
& \text { - Segmentations } \\
& \text { - Duration }
\end{aligned}
$$

\section{Machine Learning}

This study is concerned with how machine learning can facilitate accurate decision making in the MAM processes in the context of multimedia content providers.

- Archives

The MAM system must first be 'taught' to automatically recognise what is fed to it [4]. While MAM is conducive to machine learning [5], archivist have manually coded large volumes of data for transactions at the front end of the MAM process.

The system in use at the archives has the capacity to recognise the metadata field of the house format. Here files are stored in "OP1" and "OPATEM" formats. News content is stored separately in DALET and OCTOPUS formats. The system will automatically track and upload the required content and classify, store, tag and provide essential data for users. For example, if you do not tag the photo of "Tunku Abdul Rahman, the 1st Prime Minister", the system will just tag the closest generic name such as "a Malay Man". When fields are empty, the metadata entry now has to be researched and entered manually'.

- Content and Branding QC

The main QC feature before ingestion include content QC and technical QC. Producers at the source manage self-censorship of content but censorable content can always slip by. This censorship is guided by (1) the guidelines found in the Film Censorship Act 2002 [15] and (2) the Broadcasters' Content Code 2004 [16]. (Table 2).

\section{Table 2: Content and Branding QC criteria.}

\section{Criteria for content and branding QC}

- $\operatorname{MCMC}(1998)$ sections 211, 212, 232

- Content Code 2004 criteria

- Race, religion, racism sensitivities

- Political alignment

- Program, products congruent to station branding guidelines.

Broadcast stations will remind producers of their QC obligations at the stage of pitching. Next, the same content will undergo a second review after the final edit to address sensitivities such as racism, 
incongruent politics not appropriate for airing and branding QC. The content QC also comments on audio-visual quality. Subjective evaluation has is done by experienced producers. The MAM system cannot perform this.

- Technical QC

At the technical QC, the machine takes over the evaluation of content. The machine is calibrated with the expected range of technical compliance parameters that the content should match.

The volume of content coming in for $24 / 7$ broadcasts. The old system of deck-to-deck QC was humanly not possible. Machines have now taken over this portion of the workflow. After the QC evaluation, producers are updated about the corrective action to be taken. Producers and vendors sometimes make corrections up to four times. This is an outcome of using non-compliant equipment at the shooting and editing stages. They need to convert to the same Apple, Adobe Premier or AVID formats used by the station.

Three basic checks are carried out at the technical QC. The first check is for white luminance that must come from the colour bar only. The camera in use must generate the colour bar, and the programme continues on the same luminance. If the measurement of white luminance of the colour bar is higher than $700 \mathrm{mV}$, there will be a whitewash or 'clipping' in the content. Such picture quality is unacceptable.

The second check is for chrominance on colour. The camera must reproduce true colour. For example, when a yellow shirt during recording is seen as yellow-green during transmission, it is caused by a poor calibration of chrominance at the source. The TV station in question can be sued. There are two standards of chrominance: $75 \%$ and $100 \%$. Most Asian countries use the Asia-Pacific Broadcasting Union (ABU) standard of $75 \%$ (Table 3).

Table 3: Criteria for technical QC recognised by MAM.

\section{Criteria for technical QC and evaluation}

- Luminance @ $700 \mathrm{mV}$ or $0.7 \mathrm{~V}$ on the white area, to check white colour from the colour bar only.

- Chrominance on Colour. Two standards of chrominance: $75 \%$ and $100 \%$. The ABU standard Malaysia uses is $75 \%$. Only USA and Japan use $100 \%$ chrominance level.

- Audio level generated from colour bar @ tone by dB full-scale $-18 \mathrm{~dB}$

The third check is on the sound level. When recording sound, there is an audio tone and a colour bar. The tone must be generated at the source using $\mathrm{dB}$ full-scale $-18 \mathrm{~dB}$ if this is not calibrated and monitored correctly at the recording, then audio level at transmission will be poor.

Vendors have to correct, re-edit and reproduce their content to its recommended quality when their materials are rejected. This is a very expensive and tedious process. Vendors are happy to comply after they have migrated with the file-based format, which does simplify matters. The issue is different broadcasters demand differing submission formats that are only compliant to their systems and workflow. Small company producers and vendors, "...encounter the prospect of reinvesting large amounts of resources to comply" as they put it. "At times, upon checking, our recordings are in compliance, but station machines are not calibrated accordingly", producers lament.

\section{Conclusion}

The challenges effected by the industrial revolution 4.0 have caused mainstream broadcasters to opt for machine-learning features to be installed in its workflow. This exploratory study have arrived at three conclusions:

1) Broadcast stations show great potential to manage their technological disruptions and greatly improve efficiency of their broadcasting processes when they completely migrate to digital standards adopting a Media Asset Management with AI intelligent compliant systems.

2) Broadcasters and vendors will improve efficiency when they adopt and adhere to MAM approved standardized formats of archival and retrieval and request SMEs to align their production and submission to the recommended quality compliance standards.

3) Efficiency and effectiveness of SMEs' workflow will greatly improve contingent to a mature job-fit pool of talents who are able to adapt to technological changes and comply with the expected content, branding and technical standards of compliance of their broadcasting stations.

While the machine learning processes have partly taken the burden off human dependency, the accuracy of some sections of metadata entries and the programme content QC still depend on human intervention. There have been grievances raised among the technical community about the machines taking over their job functions, but the volume of content turnover is unmanageable, and thus it is inevitable for machines to take over eventually.

Machine learning does facilitate the MAM workflow. Its automatic recognition of content as per the indexed information works at will. What is not currently possible by the machine is only caused by the human error. Technical QC only enhances the quality of station broadcasting. It is still left to producers and vendors to comply with such regimens to manage the MAM system efficiently.

In conclusion, DAM/MAM processes from archiving, through systematic content documenting; up to on-air transmission are an important component of broadcasting, where quality and efficiency of talents are priority. The availability of a scaled down MAM compliant model would ensure seamless production processes for the less endowed broadcasters and vendors. The availability of set standards would achieve zero or minimal rejection at the technical and content QC stages before transmission. This would largely improve assets management processes and their workflow contingent to a job-fit mature talent force. 


\section{REFERENCES}

[1] K. Schwab, The Fourth Industrial Revolution. Penguin Random House. UK, 2017.

[2] J. Müller, Designing and building the post-analogue audio visual archive. Journal of Digital Media Management, Volume 5 / Number 3 / SPRING 2017, pp. 259-274(16). Henry Stewart Publication//I/I/

[3] J. Bancroft, The challenges of selecting a broadcast MAM solution. TVB Europe. Retrieved September 5, 2017, from https://jeffersonal.issuu.com/newbayeurope/docs/tvbe_jan17

[4] S. Wager, Digital asset management, media asset management, and content management: From confusion to clarity. Journal of Digital Asset Management, pp. 40-45, 2005.

[5] I. Zarwell, Frame-by-frame: The Ephemeral Films Project. In Journal of Digital Media Management, Volume 5 / Number 2 / WINTER 2016-2017, pp. 151-162(12). Henry Stewart Publication.

[6] C. Breaden, C. Holmes, A. Kroh, Beyond oral history: Using the Oral History Metadata Synchronizer to enhance access to audiovisual collections. Journal of Digital Media Management, Volume 5 / Number 2 / WINTER 2016-2017, pp. 133-150(18). Henry Stewart Publications.

[7] L. T. Phang, and Y.W. Soh, Tools and technologies for enhancing access to audiovisual archives: The Singapore journey. Journal of Digital Media Management, Volume 5 / Number 3 / WINTER 2016-2017, pp. 216-227(18). Henry Stewart Publications.

[8] DigitalAssetManagement.com, Metadata Quick Start. [Online] Retrieved January 15, 2018, from https://p.widencdn.net/etbk5m/DAM.com-Metadata-Quick-Start

[9] K. Curtis, and O. Draper, Multimedia Content Management - Provision of Validation and Personalisation Services. To appear in proceedings of IEEE Multimedia Systems '99, Florence, Italy, June 1999.

[10] IEEE Learning Objects Metadata URL Retrieved July 15, 2018, from http://grouper.ieee.org/groups/ltsc/wg-c.htm

[11] J. Rowe, and F. Churchville, Content Management System (CMS) 2016. Retrieved September 1, 2017from http://searchcontentmanagement.techtarget.com/definition/content-mana gement-system-CMS

[12] J. E. Lederman, Digital Media Management For Cultural Research Initiatives. University of Oregon, 2014.

[13] G. S. Becker. 1985, Jan. Human Capital, Effort, and the Sexual Division of Labor. Journal of Labor Economics, University of Chicago Press Journals, Volume 3, Number 1, Part 2, Jan., 1985. Available at https://www.journals.uchicago.edu/doi/abs/10.1086/298075

[14] Boyatzis, R. E., The Competent Manager: A Model for Effective performance. New York: John Wiley \& Sons, 1982.

[15] DAM Foundation Consultancy, 'The DAM Maturity Model', available at http:/dammaturitymodel.org Retrieved 26.12.2018, 2017

[16] N. Denzin, and Y. Lincoln, Handbook of Qualitative Research. Thousand Oaks. California: Sage Publications, 2000.

[17] K. DeWalt, and B. DeWalt, Participant Observation: a guide for fieldworkers. Walnut Creek, CA: Alta Mira Press, 2002.

[18] LPF - The National Film Censorship Board of Malaysia, Ministry of Home Affairs. Retrieved March 18, 2018 from http://lpf.moha.gov.my/lpf/index.php/ms/

[19] The Malaysian Communication and Multimedia Content Code, The Commissioner of Law Revision, Malaysia, in collaboration with National Printers, Malaysia, 2014.

\section{AUTHORS PROFILE}

Author-1

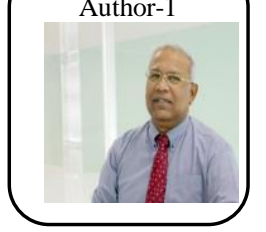

Dr. Ramachandran Ponnan is Associate Professor at the School of Media and Communication, Taylor's University, Malaysia. He has been a practicing broadcaster at the National Radio TV station for over thirty years. He teaches and publishes on broadcasting related subjects.
Dr. Mahadevan Subramaniam is the Director of Reseach and Innovation Management Centre' and the Institute of Graduate Studies. He has published widely. Diverse background in managerial and technical areas with expertise including R\&D, Research commercialisation, project management, business development and Enterprise Resource Planning (ERP).

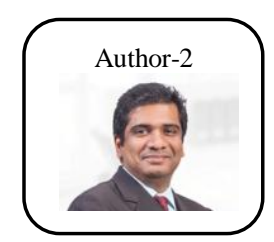

Dr. Azween Abdullah is Associate Professor of

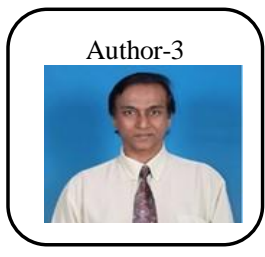
Computer Science and Cyber Security at the School of Computing and IT, Faculty of Innovation and Technology, Taylor's University. He has more than thirty years of experience as an academic in institutions of higher learning and as director of research. He has contributed vastly as a professional development alumni of Stanford University and MIT. He is vice-president for educational consultancy services, fifteen years in commercial companies as Software Engineer, Systems Analyst and as a computer software developer and IT/MIS consultancy and training. He hold several grants, his works are widely cited 